Available online at website :

http:/ / e-journal.adpgmiindonesia.com/index.php/jmie JMIE: Journal of Madrasah Ibtidaiyah Education, 5(1), 2021, 95-109

\title{
IMPLEMENTASI PROGRAM ECOPRENEURSHIPPADA SISWA ATTENTION DEFICIT HYPER ACTIVITY DISORDER (ADHD) DI SEKOLAH DASAR INKLUSIF
}

\author{
Sani Aryanto ${ }^{1)}$, Febi Junaidi ${ }^{2}$, Tatat Hartati $^{3)}$, Rahman $^{4)}$ \\ Universitas Bhayangkara Jakarta Raya ${ }^{1)}$ Universitas Sebelas Maret2), \\ Universitas Pendidikan Indonesia3)4 \\ E-mail: sani.aryanto@dsn.ubharajaya.ac.id¹), febijunaidi@student.uns.ac.id²), \\ tatat@upi.edu³),rahman@upi.edu ${ }^{4}$
}

Submit: 15 Juli 2020, Revisi: 26 Januari 2021, Approve:19 Mei 2021

\begin{abstract}
This research was conducted to describe the implementation of ecopreneurship program in ADHD students including: the characteristics, approach / method, parties involved, the impact, and the obstacles of implementation ecopreneurship program in ADHD students in Inclusive Elementary School. This research uses qualitative approach with case study method conducted at SDN Cibabat Mandiri 2 Kota Cimahi. The subject of this study was ADHD students as the primary informant supported by secondary data from orthopedagog, classroom teachers, and extracurricular teachers. Based on the results of the research that has been done, it can be known that ADHD students have very active characteristics and tend to be impulsive when participating in ecoprenuership programs, but the assited learning approach through scaffolding method is the key to the teacher's success in directing ADHD students to stay focused on the ecopreneurship program. The implementation of ecoprenuership program has 3 main impacts on the development of ADHD students, including: (1) Internalization of ecoprenuership values; (2) improvement of life skills; and (3) the creation of social interactions as an effort to improve the competence of ADHD students. The results of this study are new findings and can be used as a reference for Inclusive Elementary School in providing an overview of the internalization of ecopreneurship values in ADHD students as a reference for teachers or orthopedagog in developing innovative environmentally based learning patterns in ADHD students in Inclusive Elementary School.
\end{abstract}

Keywords: Ecopreneurship, ADHD, Inclusive Education

Pengutipan: Sani Aryanto, dkk. (2021). Implementasi Program Ecopreneurship pada Siswa Attention Deficit Hyper Activity Disorder (ADHD) di Sekolah Dasar Inklusif. JMIE: Journal of Madrasah Ibtidaiyah Education, 5(1), 2021, 95-109. jmie.v5i1.221.

Permalink/DOI: http://dx.doi.org/10.32934/jmie.v5i1.221 


\section{PENDAHULUAN}

Pada akhir tahun 2019, dunia menghadapi Pandemi Covid-19 yang berimpliksi terhadap tatanan kehidupan yang tidak berjalan normal seperti biasanya. Lonjakan korban berimplikasi angka mortalitas yang menunjukan fluktuasi maksimum.(Singh and Subedi, 2020). Virus yang disinyalir berasal dari Wuhan memberikan dampak terhadap modifikasi kebijakan dalam beberapa bidang, hal ini mengakibatkan perubahan pola interaksi dalam kehidupan sehari-hari. (Fan et al., 2020; Sanchis-Gomar et al., 2020). Berbagai upaya telah dilakukan dan salah satu upaya kuratif yang mulai diimplementasikan adalah penerapan era "New Normal' untuk mengantisipasi permasalahan-permasalahan yang kerap terjadi selama masa Covid-19 terutama di bidang ekonomi, sosial, lingkungan, dan pendidikan (Bikdeli et al., 2020).

Covid-19 menjadi bahan refleksi negeri ini karena musibah yang terjadi tidak lepas dari pola perilaku manusia yang bertindak tanpa mengindahkan sistem ekologis. Walaupun Indonesia diyakini memiliki potensi demografi yang sangat baik dan diperkirakan mengalami masa keemasan di Tahun 2045 (Aryanto, 2016) nyatanya dengan adanya musibah Covid-19 seolah menjadi indikator bahwa Indonesia harus terus berbenah dan mencari upaya solutif secara preventif maupun kuratif dalam menghadapi permasalahan-permasalahan yang terjadi hingga saat ini (Kiky, 2020).

Hasil Global Competitive Index yang merupakan laporan tahunan dari Forum Ekonomi Dunia dengan memasukan 125 negara menunjukan bahwa Indonesia berada diperingkat 38. Pencapaian itu belum dapat dikategorikan baik apabila melihat potensi kuantitas demografi Bangsa Indonesia. Akan tetapi secara kualitas, Bangsa Indonesia memiliki tiga permasalahan utama, diantaranya: Pertama permasalahan ekonomi yang disebabkan perilaku produktif lebih sedikit dibandingkan dengan perilaku konsumtif, Kedua permasalahan lingkungan alam. Ketiga, permasalahan pendidikan terutama di bidang kependidikan dasaran yang masih bersifat segregasi dan terbatasnya penyelenggaraan pendidikan inklusif. (Aryanto and Widiansyah, 2019; Aryanto et al., 2019) Ketiga permasalahan tersebut merupakan prioritas yang harus dituntaskan di tengah musibah Covid-19.

Ecopreneurship dipandang sebagai solusi dan opsi terbaik dalam mengakomodasi ketiga permasalahan utama yang dihadapkan Bangsa Indonesia. Secara terminologi, ecopreneurship berasal dari dua konsep utama meliputi: konsep ecolitercy dan entrepreneurship. Secara konseptual ecolitercy adalah sebuah pendekatan simbolis dan khusus terhadap lingkungan alam, sederhananya bahwa konsep ini menekankan pada manusia sebagai bagian makhluk hidup yang tidak lepas dari sistem ekologis sehingga secara alamiah sistem alam menjadi peletak dasar dalam berprilaku (Ekayanti et al., 2011; Uslu, Hancioğlu and Demir, 2015; Nadiroh and Siregar, 2019). Sedangkan Entrepreneurship atau kewirausahaan ,erupakan sifat, ciri, dan watak seseorang yang memiliki kemauan dalam mewujudkan gagasan inovatif ke dalam dunia nyata.

Kedua konsep tersebut menjadi landasan terminologi dalam mewujudkan konsep ecopreneurship secara definitif. Oleh karena itu, secara definitif, konsep ecopreneurship adalah konsep yang mengarahkan manusia sebagai bagian dari sistem alam dan mampu menginternalisasikan nilai-nilai kewirausahaan sebagai landasan dalam berperilaku termasuk mempertimbangkan 
dampak dari perilaku wirausaha (Dixon and Clifford, 2007; Nacu and Avasilcăi, 2014; Schaltegger, 2014; Aryanto and Syaodih, 2017).

Konsep ini pertama kali dikembangkan oleh Schaper yang mendefinisikan ecopreneurship sebagai bentuk wirausaha yang berwawasan lingkungan dalam menjalankan usahanya (Schaper, 2002). Pada mulanya konsep ini diimplementasikan di dunia ekonomi dan belum secara masif diinternalisasikan dalam berbagai bidang, termasuk bidang pendidikan terlebih dalam penyelenggaraan pendidikan inklusi.

Pendidikan inklusi dipandang sebagai salah satu opsi terbaik dalam menjembatani tujuan pendidikan untuk semua dan dianggap sebagai langkah dalam menginternalisasikan nilai-nilai ecoprenuership dalam dunia pendidikan (Pratiwi, 2015). Pendidikan inklusi adalah suatu pendekatan pendidikan yang inovatif dan strategis untuk memperluas akses pendidikan bagi semua anak, termasuk dengan anak disabilitas (Indriawati, 2013; Sulistyadi, 2014; Wati, 2014) sehingga penanaman nilai-nilai ecopreneurship tidak hanya terbatas pada siswa normal saja, melainkan secara masif diinternalisasikan kepada semua jenis siswa termasuk siswa berkebutuhan khusus penyandang ADHD. Penelitian ini secara khusus mengkaji proses internalisasi nilai-nilai ecopreneurship pada siswa ADHD sebagai tindak lanjut penelitian sebelumnya yang dilakukan oleh Aryanto (2018) yang mengkaji tentang "Implemetasi Program Ecopreneurship di Sekolah Dasar Inklusif'.

Subjek utama penelitian ini adalah siswa penderita ADHD, hal ini disebabkan karena penderita ADHD di Indonesia cukup tinggi angkanya mencapai 26,4\%. Berdasarkan Badan Pusat Statistik Nasional (BPSN) Tahun 2007 terdapat 82 juta populasi anak di Indonesia mengalami gangguan kesehatan jiwa, tercatat satu diantara lima anak dan remaja dibawah usia 18 tahun mengalami masalah kesehatan jiwa dan sedikitnya 16 juta anak mengalami ADHD (Hayati and Apsari, 2019; Lake et al., 2019). Gangguan hiperaktivitas ini dapat dijumpai dalam kehidupan sehari-hari pada anak usia sekolah sampai remaja, bahkan apabila tidak segera ditangani maka akan berpengaruh kepada masa depan seseorang.

SDN Cibabat Mandiri 2 Kota Cimahi merupakan tempat penelitian yang dianggap representatif dalam menggambarkan proses internalisasi nilai-nilai ecopreneurship pada siswa ADHD melalui metode studi kasus dikarenakan sekolah ini termasuk sekolah rujukan dalam penyelenggaraan pendidikan inklusi di Kota Cimahi. Hasil penelitian ini diharapkan menjadi referensi setiap sekolah penyelenggara pendidikan inklusif yang memiliki siswa ADHD dalam memberikan perlakuan dan layanan yang tepat selama proses internalisasi nilai-nilai ecopreneurship.

\section{METODE}

Metode studi kasus dianggap sebagai metode penelitian yang paling tepat dalam memberikan gambaran kemampuan siswa ADHD selama melaksanakan program ecopreneurship di SD Inklusif. Metode ini dianggap mampu mengungkap fenomena menjadi jauh lebih detail karena orientasi dan skema penelitian yang berorientasi pada kasus. Penelitian ini dilakukan selama 5 bulan dengan langkah-langkah sebagai berikut. (1) Pemilihan tema, topik, dan kasus; (2) pencarian literatur yang relevan setelah memilih tema, topik, dan kasus yang tepat; (3) Pengumpulan data dan informasi yang diperoleh dari lapangan sesuai dengan kasus yang telah 
ditentukan, dalam hal ini peneliti menggunakan informan dan teknik-teknik pengumpulan data untuk menjawab rumusan masalah penelitian; (3) analisis data dengan membaca keseluruhan data, melakukan pengkodean data (coding), mendeskripsikan hasil coding, dan interpretasi data (4) membuat simpulan, sintesis, dan implikasi berdasarkan temuan-temuan penelitian (Aryanto et al., 2019). Berdasarkan langkah-langkah tersebut, peneliti lebih mudah menginterpretasikan hasil temuan secara lebih komprehensif yang didasarkan pada fakta-fakta, data/informasi sebanyak mungkin mengenai kemampuan siswa ADHD dalam melaksanakan program ecopreneurship di SD Inklusif.

SDN Cibabat Mandiri 2 Kota Cimahi merupakan sekolah pusat rujukan penyelenggaraan pendidikan inklusif di Kota Cimahi dan dianggap sebagai tempat yang sangat representatif dalam melakukan penelitian ini karena secara implisit program ecoprenuership sudah berjalan dengan baik. Adapun subjek penelitian ini diantaranya: seorang siswa ADHD, seorang Guru Pendamping Khusus (GPK), seorang ahli orthopedagog (ahli bidang pendidikan luar biasa), dua orang guru kelas yang diharapkan memberikan informasi aktual dan akuntabel melalui proses triangulasi data yang terdapat dalam Tabel 1.

Tabel 1. Teknik Triangulasi dan Instrumen Penelitian

\begin{tabular}{cc}
\hline Teknik Pengumpulan Data & Instrumen Penelitian \\
\hline Wawancara & Pedoman Wawancara \\
Observasi & Catatan Lapangan \\
Studi dan Analisis Dokumen & Dokumentasi Foto \\
\hline & Sumber : (Aryanto et al., 2019)
\end{tabular}

Disamping itu, agar data yang diperoleh jauh lebih mendalam dan komprehensif, peneliti juga melakukan kajian literatur secara selektif sehingga hasil penelitian ini benar-benar representatif sesuai dengan kebutuhan.

\section{HASIL DAN PEMBAHASAN}

\section{Karakteristik dan Tujuan Program Ecoprenuership bagi Siswa ADHD}

Attention Deficit Hyperactivity Disorder (ADHD) yaitu sebuah gangguan pada perkembangan otak yang menyebabkan penderitanya menjadi hiperaktif, impulsif, serta susah memusatkan perhatian. Kondisi ini dulunya dikenal dengan ADD atau Attention Deficit Disorder (Clarke et al., 2019). ADHD merupakan kelainan secara neurologis pada anatomi otak (Lake et al., 2019). Gejala perilaku yang paling tampak dari siswa ADHD yakni menunjukan suatu pola gigih dalam mencari perhatian dan/ atau hiperaktif/ impulsif yang terjadi lebih sering dan lebih hebat daripada yang biasanya teramati pada orang-orang dengan tingkat perkembangan setaraf (Bellato et al., 2020; Boehme et al., 2020). Anak-anak yang mengalami ADHD akan berkesulitan dalam mengendalikan perilaku dan/atau memusatkan perhatian. 
Berdasarkan hasil obeservasi, terdapat 5\% siswa yang mengalami ADHD di SDN Cibabat Mandiri Kota Cimahi, salah satunya ST. ST kini berusia 15 tahun, seharusnya ST sudah duduk di bangku kelas 3 SMP atau kelas 1 SMA, namun karena sempat ditolak 5 sekolah mau tidak mau akhirnya ST baru bisa bersekolah di usia 9 tahun. Penolakan ST disebabkan karena sebagian besar orang memiliki anggapan bahwa ST gila sebelum akhirnya diketahui bahwa ST mengalami ADHD, dan sayangnya justifikasi itu muncul dari beberapa guru yang menolak ST di sekolahnya. Berdasarkan hasil wawancara dengan GPK nya dapat diketahui bahwa orang tuanya semakin putus asa dan sempat berpikir untuk tidak menyekolahkan ST. Tapi beruntungnya kini ST bisa bersekolah di SDN Cibabat Mandiri 2 Kota Cimahi walaupun dengan usia yang relatif remaja.

"Masuk SD dalam usia 9 tahun sehingga saat ini dia berusaha hampir 15 tahun yang berarti seharusnya sudah SMA. Dia mengalami pengalaman yang cukup menyedibkan karena pernah ditolak. di 5 sekolah sebelum akbirnya di sekolah kan di sekolah ini. Banyak orang-orang yang belum mengenal dan mengetahui hambatan ST sehingga mereka bilang babwa ST gila. Sampai orang tuanya hampir putus asa mengingat kondisi ST yang demikian dan tidak di terima di 5 sekolah. ADHD yang dialami ST terbatas pada tingkeat konsentrasinya yang tidak fokus sehingga dia jarang mengerjakan PR atau tugas yang diberikan guru. Secara kognitif dia seperti anak normal pada umumnya, tapi sayangnya dia tidak bisa fokus dan konsentrasi sehingga menghambat pada kemampuannya selama pembelajaran. ST juga agak emosional dan terkadang tidak terkontrol, namun setelab kelas VI dia lebih stabil dan mudah dikendalikan."

Sumber data : Hasil Wawancara dengan GPK (TA)

Penyebab ADHD sampai saat ini belum diketahui secara pasti, namun hal ini bisa disebabkan pada kinerja dan perkembangan otak. Selain itu, terdapat tiga faktor yang dianggap memungkinkan ternjadinya ADHD, yaitu: genetik/keturunan, ketidakseimbangan kimia dan kinerja otak (Bellato et al., 2020). Pada anak yang menderita ADHD, didapati bahwa area otak yang mengontrol perhatian tampak tidak terlalu aktif, dibandingkan dengan anak-anak lainnya yang tidak menderita ADHD.

Berdasarkan hasil wawancara dengan GPK dan Guru kelasnya ada beberapa kemungkinan penyebab ST mengalami ADHD, salah satunya adalah ketika di usia kandungan 7 bulan perkembangan janin ST sudah diketahui berbeda dengan anak normal pada umunya, hal itu terlihat dari bentuk kepala ST yang tidak proporsional dengan tubuhnya, dan hal tersebut yang memungkinkan penyebab kinerja otak ST tidak seperti anak normal pada umumnya, lebih jelasnya dapat dilihat melalui hasil wawancara di bawah ini.

"Kalau ST berdasarkan keterangan ibunya, di usia kandungan 2-6 bulan tidak ada permasalahan, namun ketika usia kandungan 7 bulan berdasarkan hasil USG bentuk kepala ST kecil dan sudah dipastikan akan lahir dalam kondisi berkebutuhan khusus, namun orang tuanya menerima sampai akbirnya sekarang terlahir dalam keadaan berkebutuhan khusus."

Sumber data : Hasil Wawancara dengan Guru Kelas VI

"Belum diketahui pasti penyebab ST ADHD karena apa, namun saya menduga dia dikarenakan faktor kondisi ibunya ketika hamil ST mengalami tekanan batin karena perceraian dengan suaminya 
Sani Aryanto, dkk.

yang mengakibatkan ST ADHD seperti saat ini. Dan ada kemungkinan kecil faktor keturunan terlebih kakaknya juga mengalami ADHD seperti ST, sayangnya kami tidak bisa memberikan keterangan lebih lanjut karena ibunya yang tidak terbuka pada saya. Namun yang saya tabu ST terkesan agak kurang dipedulikan ibunya karena broken home, sebingga ibunya lebih sering membiarkan anaknya dan fokus mencari nafkeah untuk kedua anaknya."

Sumber data : Hasil Wawancara dengan GPK (TA)

Banyak kemungkinan yang menyebabkan ST mengalami ADHD, walaupun sampai saat ini belum diketahui secara pasti penyebab utama ST mengalami ADHD dikkarenakan faktor apa, namun yang sangat disayangkan melihat kondisi ST yang ADHD nyatanya ST adalah salah satu siswa ABK yang kurang mendapatkan perhatian dari ibunya, salah satu contohnya karena konsekuensi anak yang mengalami ADHD itu sangat mudah lupa, ST adalah peserta didik yang paling tidak disiplin salam mengerjakan setiap pekerjaan rumah yang diberikan oleh gurunya, dan hal tersebut diperparah karena perhatian ibunya yang kurang terhadap ST. Pihak gurunya sudah mencoba mengkomunikasikan secara baik-baik ke ibunya namun responnya terkadang tidak jelas tindak lanjutnya hingga akhirnya gurunya selalu memakluminya. Bahkan lebih parahnya lagi ST itu termasuk anak yang paling cepat datang ke kelas namun dia juga adalah siswa yang paling terkahir dijemput oleh ibunya yang mengindikasikan bahwa ST kurang perhatian dari orang tuanya.

Dalam kesehariannya, ST dikenal sebagai anak yang periang walaupun dia terkadang sering jahil dengan teman-temannya. Terkadang teman-teman sebayanya tidak terlalu suka berinteraksi dengan ST, dikarenakan konteks bercanda yang dilakukan oleh ST di mata temanteman sekelasnya tidak terlalu lucu. Hal tersebut yang membuat ST lebih suka bergaul dengan adik kelasnya yang usianya jauh berada di bawah ST, karena hampir sebagian besar adik kelas ST dapat menerima candaan ST. Namun apabila dalam konteks pembelajaran, ST adalah salah satu siswa yang perlu mendapatkan perhatian khusus, karena berkaitan dengan riwayat ADHD yang dialaminya yang mengakibatkan ST tidak pernah bisa fokus, seperti yang disampaikan oleh GPK dan guru kelasnya melalui hasil wawancara di bawah ini.

"Keseharian di kelasnya dia tidak pernah bisa diam, paling bertahan hanya sekitar 5 menit saja setiap dia mengikuti pembelajaran apalagi ST adalah salah satu pembuat onar di kelas, sehingga guru kelasnya sering membiarkan ST untuk. ke luar kelas sesuai dengan keinginan ST, oleb karena itu ST lebih sering ditangani oleh saya sebagai guru GPK nya. Karena kemampuannya yang tidak bisa fokus sehingga sangat sulit untuk menerima segala macam informasi yang ada".

Sumber data : Hasil Wawancara dengan GPK (TA)

"Sedangkan ST karena usia kronologisnya berbeda dengan usia mentalnya maka saya tidak terlalu menekankan kemampuan ST secara akademik, saya lebih menekankan ke sosialisasi di kelas. Jadi saya lebih meminta bantuan ke GPK”.

Sumber data : Hasil Wawancara dengan Guru Kelas VI (RH) 
ST lebih sering ditangani oleh GPKnya, sehingga GPK nya sudah sangat mengenal ST dan mengetahui cara tepat dalam menangani ST termasuk dalam memberikan pemahaman terkait program ecopreneurship pada ST. Dalam mengikuti kegiatan ecopreneurship, ST dikenal sebagai salah satu siswa yang sangat antusias dalam melaksanakan kegiatan tersebut, ST selalu ingin mengambil peran dalam setiap bagian tugas yang diberikan GPK.

Dalam pengembangannya, program ecopreneurship bagi siswa ADHD tidak terlalu menekankan pada aspek kognitif namun lebih ditujukan pada aspek apektif dan psikomotor yang diharapkan mampu melatih kemampuannya dalam berinteraksi, berkomunikasi, dan beradaptasi. Tujuan program ecopreneurship siswa ADHD disesuaikan dengan muatan kurikulum 2013 yang diturunkan kedalam beberapa tujuan program ecopreneurship. Lebih jelasnya terkait dengan tujuan setiap jenis program ecopreneurship untuk siswa ADHD dapat dilihat melalui Tabel 2.

Tabel 2. Jenis dan Tujuan Program-Program Ecopreurship bagi Siswa ADHD

\begin{tabular}{|c|c|c|}
\hline No & Nama Program & Tujuan Program \\
\hline 1. & Hunting Sampah & $\begin{array}{l}\text { 1. Untuk membiasakan siswa ADHD mencintai lingkungan } \\
\text { sekitarnya } \\
\text { 2. Siswa ADHD terbiasa untuk memilah sampah sesuai } \\
\text { dengan jenisnya }\end{array}$ \\
\hline 2. & Ecobrick & $\begin{array}{l}\text { 1. Memberikan edukasi kepada siswa } A D H D \text { dalam } \\
\text { pemanfaatan sampah yang efektif dan efisien. } \\
\text { 2. Membiasakan siswa } A D H D \text { untuk memperlakukan } \\
\text { sampah dengan kreatif. }\end{array}$ \\
\hline 3. & Bank Sampah & $\begin{array}{l}\text { 1. Membiasakan siswa } A D H D \text { dalam memperlakukan } \\
\text { sampah secara bijaksana } \\
\text { 2. Memberikan pemahaman siswa } A D H D \text { bahwa sampah } \\
\text { dapat bernilai dan mampu menjadi salah satu cara untuk } \\
\text { mendapatkan uang }\end{array}$ \\
\hline 4. & $\begin{array}{l}\text { Pembiasaan } \\
\text { pemilahan } \\
\text { sampah organik } \\
\text { dan anorganik } \\
\text { (OGI-OGA) }\end{array}$ & $\begin{array}{l}\text { 1. Membiasakan siswa ADHD membuang sampah } \\
\text { berdasarkan jenis sampahnya. } \\
\text { 2. Memberikan edukasi berkaitan dengan pemanfaatan } \\
\text { sampah organik dan anorganik. }\end{array}$ \\
\hline 5. & $\begin{array}{l}\text { Pembuatan } \\
\text { sampah organik } \\
\text { menjadi pupuk } \\
\text { kompos (Purpose) }\end{array}$ & $\begin{array}{l}\text { Memberikan edukasi kepada siswa ADHD terkait } \\
\text { pemanfaatan dan cara memperlakukan sampah organik } \\
\text { menjadi barang yang bermanfaat }\end{array}$ \\
\hline
\end{tabular}




\begin{tabular}{|c|c|c|}
\hline 6. & Ecocraft & $\begin{array}{l}\text { Memberikan edukasi kepada siswa ADHD dalam } \\
\text { memanfaatkan sampah menjadi barang-barang yang } \\
\text { memiliki nilai jual }\end{array}$ \\
\hline 7. & Hidroponik & $\begin{array}{l}\text { 1. Memberikan edukasi pada siswa terkait penanaman tanpa } \\
\text { menggunakan media tanah } \\
\text { 2. Efektivitas penggunaan lahan yang tidak ada media tanah, } \\
\text { sehingga memungkinkan siswa ADHD dalam } \\
\text { memanfaatkan lahan sempit di lingkungan sekolah. }\end{array}$ \\
\hline 8. & $\begin{array}{c}\text { Masak Bersama } \\
\text { (MAMA) }\end{array}$ & $\begin{array}{l}\text { 1. Memberikan keterampilan memasak pada siswa } \\
\text { berkebutuhan khusus sebagai bekal ketika bermasyarakat. } \\
\text { 2. Memanfaatkan hasil olahan hidroponik }\end{array}$ \\
\hline 9. & Market Day & 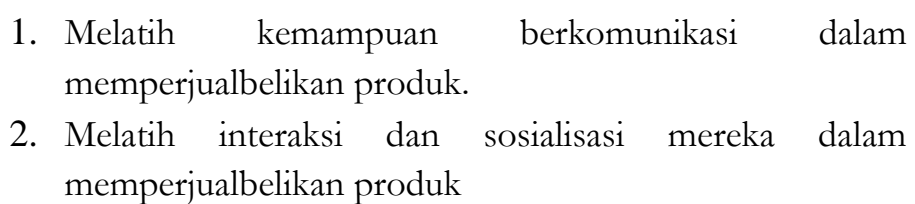 \\
\hline
\end{tabular}

Program-program dalam tabel 2 dianggap merepresentasikan konsep ecopreneurship karena sebagian besar tujuan program diarahkan pada perilaku kewirausahaan yang diimbangi dengan kecintaan terhadap lingkungan alam yang memandang dan menilai potensi sumber daya dan peluang terserap melalui lensa komitmen lingkungan alam (Dixon and Clifford, 2007)

\section{Pihak-Pihak yang Terlibat dalam Pelaksanaan Program Ecoprenuership bagi Siswa ADHD}

Inisiator pengembangan program ecopreneurship yang dikembangkan di SDN Cibabat Mandiri 2 Kota Cimahi adalah Guru Pendamping Khusus (GPK) dan ahli orthopedagog, sehingga dalam pengembangannya program ini tidak lepas dari pernanan GPK dalam menentukan pihakpihak yang terlibat selama merumuskan, menjalankan dan memberikan penilaian program ecopreneurship. Berikut adalah beberapa pihak yang terlibat dalam pengembangan program ecopreneurship di SDN Cibabat Mandiri 2 Kota Cimahi, diantaranya: siswa normal, guru kelas, kepala sekolah, orang tua siswa, guru ektrakurikuler dan pihak-pihak yang sengaja diundang karena memiliki keahlian di bidang tertentu. Setiap pihak-pihak yang terlibat memiliki tugasnya masing-masing dengan entitas yang berbeda-beda namun memiliki tujuan yang sama yaitu terciptanya program ecopreneurship yang mampu mengakomodir kebutuhan para siswa ADHD.

Pertama, GPK dan ahli orthopedagog merupakan pihak yang sangat berpengaruh selama pengembangan program ecopreneurship. Apalagi di sekolah ini kedua pihak ini merupakan perintis atau pelopor dalam mengembangkan program ecopreneurship sebagai bentuk inovasi pembelajaran yang dikhususkan pada siswa ADHD. Kedua pihak ini memiliki pernanan penting dalam merancang, melaksanakan, dan memberikan penilaian kepada seluruh siswa ADHD yang terlibat dalam program ini. Kedua pihak ini juga yang mengkoordinasikan dengan pihak-pihak 
lainnya yang terlibat selama pengembangan program ecopreneurship di sekolah ini. Kedua, keterlibatan guru kelas dalam pengembangan program ecopreneurship memang tidak terlalu signfikan seperti GPK dan ahli orthopedagog. Peranan guru kelas hanya sebatas sebagai apresiator yang dalam hal ini bertindak sebagai pembeli ketika ada kegiatan market day. Disamping itu, kapasitas guru kelas juga dibutuhkan ketika mempertimbangkan kelayakan setiap program ecopreneurship yang disusun oleh GPK dan ahli orthopedagog.

Ketiga, keterlibatan kepala sekolah sama hal nya dengan pihak guru kelas yakni sebagai apresiator dan pemberi pertimbangan, namun kepala sekolah memiliki kapasitas lain yaitu berkaitan dengan komunikasi kepada pihak dinas dalam memberikan gambaran pengembangan program ecopreneurship ke pihak luar. Sehingga tidak jarang berkat kolaborasi antara GPK, ahli orthopedagog, dan kepala sekolah beberapa program di SDN Cibabat Mandiri 2 Kota Cimahi menjadi rujukan dan percontohan di sekolah lainnya, dan sekolah ini sangat diperhitungkan dalam pengembangan setiap programnya. Salah satunnya kegiatan market day yang cikal bakal nya berasal dari sekolah ini menurut penuturan GPK nya.

Keempat, siswa normal merupakan pihak yang sangat menentukan keberhasilan setiap program ecopreneurship, masalahnya keberhasilan siswa ADHD dalam mengikuti program ecopreneurship terletak pada kemampuan mereka dalam berkomunikasi, berinteraksi, dan bersosialisasi dengan teman-temanya, terlebih teman-teman yang berasal dari siswa normal. Kelima, orang tua merupakan pihak yang cukup penting dilibatkan dalam program ecopreneurship. Keterlibatan orang tua tidak bersifat teknis, artinya selama pelaksanaan program ecopreneurship, GPK dan ahli orthopedagog meminimalisir keterlibatan orang tua turun tangan secara langsung. Adapun keterlibatan orang tua yakni dalam tahap persiapan program. Sehingga guru GPK dan ahli orthopedagog akan mengkomunikasi terkait alat dan bahan yang harus dibawa para siswa atau hal-hal lainnya yang dibutuhkan selama menjalankan program ecopreneurship.

Keenam, pihak-pihak yang sengaja diundang yang dimaksud adalah pihak lain yang memiliki keahlian khusus yang tidak dimiliki oleh pihak sekolah, misalnya dalam program hidroponik. Apabila di sekolah tidak ada yang memiliki keahlian atau keterampilan khusus dalam kegiatan hidroponik, maka pihak-pihak tersebut lah yang ikut andil berperan atas dasar peertimbangan dari pihak lainnya seperti: Guru kelas, kepala sekolah, dan orang tua siswa.

Temuan dalam penelitian ini menegaskan bahwa dalam pengembangan program ecopreneurship harus disesuaikan dengan muatan kurikulum standar pemerintah, situasi, dan kondisi di sekolah sebagai salah satu upaya antisipatif dalam memberikan pengalaman berwirausaha yang berwawasan lingkungan pada diri siswa ADHD dengan tujuan agar para siswa ADHD dapat mengaktualisasikan potensi, bakat, dan minat mereka yang didasarkan pada tiga kompetensi yaitu: berkomunikasi, berinteraksi, dan bersosialisasi.

\section{Pendekatan dan Metode Pelaksanaan Program Ecoprenuership bagi Siswa ADHD}

Karakteristik yang paling tampak dari Siswa ADHD adalah sulitnya untuk berkonsentrasi dan fokus, sehingga dalam beberapa kondisi pembelajaran siswa ADHD akan mudah 
terdistraksi daya konsentrasinya ketika melihat sesuatu yang baru dihadapannya. ADHD adalah suatu kondisi yang terlihat jelas pada beberapa anak pada masa prasekolah dan pada tahun-tahun awal masa sekolah. Anak-anak yang mengalami ADHD akan berkesulitan dalam mengendalikan perilaku dan/atau memusatkan perhatian (Clarke et al., 2019). Salah satu metode yang tepat digunakan untuk siswa ADHD yaitu melalui pendampingan sceffolding dengan pendekatan assited learning seperti hal nya siswa yang mengalami sindrom autistik. Scaffolding merupakan metode yang menekankan proses interaksi antara pendidik dan peserta didik secara intensif dengan didasarkan pada kebutuhan peserta didik sebagai upaya mendorong kompetensi peserta didik dalam memecahkan suatu permasalahan dalam konteks pembelajaran melalui berbagai intervensi dan bentuk penguatan yang bersifat formulatif serta sistematis (Kaste, 2004; Van de Pol, Volman and Beishuizen, 2012; Muhonen et al., 2016; Haataja et al., 2019; Schutz, Danielson and Cohen, 2019).

Tips praktis untuk mengajar anak-anak dengan ADHD diantaranya: (1) Biarkan anak-anak yang mengalami ADHD bergerak sambil belajar. Banyak anak yang mengalami ADHD harus bergerak saat mendengarkan. Jika kita meminta mereka untuk duduk diam sambil belajar maka mereka akan menggunakan semua konsentrasi mereka untuk duduk diam sehingga akan sangat sedikit sisa konsentrasi (jika ada) yang digunakan untuk belajar. Namun, jika kita membiarkan mereka untuk memilih gerakan mereka sendiri, hampir pasti hal tersebut akan mengganggu para guru dan anak-anak lain di kelas (Hayati and Apsari, 2019). Oleh karena itu penting bagi kita untuk memilihkan kegiatan yang disukai dan nyaman untuk dilakukan oleh anak, termasuk dalam memilih aktivitas yang tepat selama kegiatan ecopreneurship (2) Berikan pada siswa daftar hal-hal yang harus dilakukan setiap hari. Hal ini akan membantu anak-anak yang mengalami ADHD untuk bertanggung jawab dan mengembangkan rasa tanggung jawab mereka. Banyak anak yang mengalami ADHD merasa ingin tahu apa yang akan terjadi selanjutnya. Mereka tidak selalu suka kejutan sedangkan menconteng setiap tugas yang sudah dilakukan merupakan kepuasan tersendiri serta membuat anak merasa sempurna sehabis menyelesaikan satu persatu tugas yang didaftarkan (Hayati and Apsari, 2019).

Temuan dalam penelitian ini mengungkapkan bahwa prinsip layanan pendidikan inklusif menjadi tolak ukur dalam memberikan intervensi pada siswa ADHD dengan mempertimbangkan kebutuhan mereka, sehingga pengembangan program ecopreneurship pada pelaksanaannya harus benar-benar mengakomodir setiap siswa ADHD.

\section{Dampak Pelaksanaan Program Ecoprenuership bagi Siswa ADHD}

Ada tiga dampak yang dirasakan oleh siswa ADHD selama melaksanakan program ecopreneurship diantaranya:

\section{a. Munculnya Nilai-Nilai Ecopreneurship pada Siswa ADHD}

Pelaksanaan program ecopreneurship berdampak terhadap munculnya nilai-nilai ecopreneurship pada siswa ADHD, walaupun menurut Mulyani, dkk. 2010 mengungkapkan bahwa dalam tahap pertama diimplementasikan nilai-nilai ecopreneurship yang diambil enam nilai pokok, yaitu mandiri, kratif, berani mengambil resiko, berorientasi pada tindakan, kepemimpinan dan kerja keras (Mulyani, dkk. 2010). Berdasarkan hasil wawancara dan pengamatan langsung terkait implementasi program ecopreurship di SDN Cibabat Mandiri 2 Kota Cimahi dapat diketahui 
bahwa nilai-nilai yang paling dominan muncul pada setiap siswa ADHD adalah kemandiriannya walaupun ST dikenal dengan peserta didik yang kurang bertanggung jawab dikarenakan setiap ada Pekerjaan Rumah (PR) jarang dikerjakan dengan alasan lupa. Berikut hasil wawancara peneliti dengan GPK terkait dengan nilai-nilai ecopreneurship yang muncul pada diri ST.

"Karena usianya sudah menginjak dewasa tingkat kemandirian sudah cukup baik, dia bisa mengerjakan sendiri apa yang dia lihat walaupun hasilnya nanggung, karena adakalanya pekerjaan dia tidak selasai oleh karena itu tanggungjawabnya sangat kurang. Namun dia adalah salah satu anak. yang suka dengan hal-hal yang baru sehingga anak. ADHD cenderung lebih besar rasa ingin tabunya. Adakalaanya dia bisa meninggalkan pekerjaannya karena dia melibat sesuatu bal yang baru dan rasa ingin tahu dan mencoba hal-hal yang baru dilihatnya."

Sumber data : Hasil Wawancara dengan GPK (TA)

\section{b. Melatih Keterampilan Siswa ADHD}

Program-program ecopreneurship yang dilaksanakan juga berdampak terhadap keterampilan siswa ADHD dalam melakukan aktivitas ekonomi mulai dari proses produksi, distribusi/marketing dan konsumsi. Sehingga guru mengupayakan memberikan pengalaman sekaligus melatih keterampilan siswa dalam melakukan aktivitas ekonomi dengan harapan kelak siswa dapat mandiri dan menyesuaikan dengan lingkungan masyarakat. Salah satu contoh praktis keterampilan yang menjadi penekanan dalam melakukan aktivitas ekonomi ini adalah pengenalan mata uang sejak dini melalui kegiatan market day. Keterampilan lainnya yang dapat dilihat adalah keterampilan dalam memperlakukan sampah mulai dari aktivitas memungut, memilah, mengolah, dan menjual sampah. Hal ini sesuai dengan teori yang disampaikan oleh (Supriatna dalam Aryanto and Syaodih, 2017) salah satu keterampilan sosial dalam program ecopreneurship diantaranya: (1) Selalu membuang sampah pada tempatnya; (2) tidak membakar sampah; (3) membersihkan sampah-sampah yang menyumbat saluran air; (4) mengolah dan memanfaatkan sampah.

Program ecopreneurship menuntut guru untuk dapat merangsang daya cipta dan kreativitas siswa dalam menciptakan sesuatu hal, berupa ide atau produk, aktif berfikir, menganalisis, mengamati, mencari celah dan merumuskan ide (Mamur 2010), sehingga berdampak terhadap keterampilan siswa ADHD dalam membuat sebuah karya yang memiliki nilai jual tetapi memperhatikan aspek lingkungan sebagai syarat mutlak dalam menghasilkan sebuah karya.

Dengan demikian banyak sekali hal-hal yang dapat dipelajari setiap siswa ADHD dalam melatih keterampilan mereka sebagai upaya untuk meningkatkan kemampuan berkomunikasi, berinteraksi, dan bersosialisasi agar dapat menyesuaikan serta diterima oleh lingkungan sekitarnya.

\section{c. Terciptanya Interaksi Sosial antara Siswa ADHD dan Siswa Normal.}

Dampak pelaksanaan program ecopreneurship yang ketiga adalah terciptanya pola interaksi antara siswa berkebutuhan khusus dengan siswa normal lainnya. Sebagian besar pola interaksi yang tercipta melalui program ecopreneurship adalah sikap empati para siswa normal terhadap siswa ADHD, sehingga tidak jarang selama proses pembelajaran siswa ADHD mendapatkan bantuan dari teman-temannya. Namun nyatanya tidak selamanya pola interaksi yang terbangun 
bernilai positif, karena dalam beberapa kondisi siswa ADHD mendapatkan tanggapan skeptis dari teman-teman disekelilingnya yang disebabkan karena emosinya yang fluktuatif dan kebiasaan tantrum tanpa alasan tertentu. Namun berdasarkan keterangan dari GPK melalui hasil wawancara dan observasi menggambarkan bahwa hampir sebagian besar siswa normal bisa memaklumi karakteristik dan kelemahan siswa ADHD karena pada dasarnya setiap guru yang berada di sekelilingnya siswa ADHD selalu memberikan pengertian dan pengarahan.

Temuan ini menegaskan bahwa keberadaan siswa normal sangat menentukan keberhasilan program ecopreneurship yang dilakukan oleh siswa ADHD, sehingga eksistensinya sangat diperlukan untuk menunjang kemampuan siswa berkebutuhan khusus dalam meningkatkan kemampuan berkomunikasi, berinteraksi dan bersosialisasi. Namun sayangnya belum ada hasil riset lainnya sebagai data komparasi terkait efektivitas pengembangan program ecopreneurship dalam membantu peningkatan pola interaksi antara siswa ADHD dengan siswa normal, karena sebagian besar riset yang terkait dengan pengembangan ecopreneurship masih berada di tataran konseptual.

\section{Hambatan-Hambatan Siswa ADHD dalam melaksanakan Program Ecoprenuership}

Peserta didik ADHD memiliki hambatan dari pola perilakunya yang sangat aktif dan tidak bisa berdiam diri. Peserta didik tersebur juga tidak bisa fokus dan konsentrasi sehingga terkadang dia terlambat memahami materi dikarenakan pola perilakunya yang mudah tertarik dengan sesuatu hal yang baru dan menarik perhatiannya dan hal ini sesuai dengan karakteristik ADHD yang disampaikan oleh UNESCO bahwa peserta didik memiliki ciri-ciri perhatian tidak jelas, hiperaktif, impulsif (UNESCO, 2009). Dalam kegiatan ecopreneurship pada dasarnya peserta didik ADHD bisa mengikuti walaupun terkadang harus dengan usaha guru dalam mengingatkan dan memberikan teguran secara berulang agar dapat menyelesaikan tugas dengan tuntas.

\section{SIMPULAN}

Implementasi program ecopreneurship pada siswa ADHD dianggap dapat dilaksanakan dengan baik, walaupun selama proses kegiatan belajar mengajar perlu ada asistensi atau pendampingan dari guru pendamping khusus. Selama pelaksanaannya, program ecopreneurship yang dikhususkan pada siswa ADHD tidak terlalu ditekankan pada aspek pengetahuan atau kognitif melainkan lebih khusus kepada aspek perilaku (afektif) dan keterampilan (psikomotor) yang diwujudkan kedalam beberapa kegiatan yang diharapkan mampu meningkatkan kemampuan siswa ADHD dalam berinteraksi, berkomunikasi, dan beradaptasi mengingat karakterististik siswa ADHD yang sangat aktif dan impulsif, namun pendekatan assited learning melalui metode scaffolding menjadi kunci keberhasilan guru dalam mengarahkan siswa ADHD untuk tetap fokus mengikuti program ecopreneurship. Selama pelaksanaan program ecopreneurship, guru tidak hanya bekerja sendiri dan dibantu oleh pihak-pihak lainnya seperti: siswa lainnya, guru kelas, kepala sekolah, orang tua, guru ektrakurikuler dan pihak-pihak yang sengaja diundang dengan keahlian di bidang tertentu. Setiap pihak-pihak yang terlibat memiliki tugasnya masing- 
masing dengan entitas yang berbeda-beda namun memiliki tujuan yang sama yaitu terciptanya program ecopreneurship yang mampu mengakomodir kebutuhan para siswa ADHD. Pelaksanaan program ecoprenuership memiliki 3 dampak utama terhadap perkembangan siswa ADHD, diantaranya: (1) Internalisasi nilai-nilai ecoprenuership; (2) peningkatan keterampilan hidup; dan (3) terciptanya interaksi sosial sebagai upaya peningkatan kompetensi siswa ADHD. Namun hambatan utama yang dihadapkan siswa ADHD adalah pola perilakunya yang sangat aktif dan impulsive sehingga menuntut perhatian serta intervensi guru agar tetap berkonsentrasi mengikuti program ecoprenuership dengan baik.

\section{DAFTAR PUSTAKA}

Aryanto, S. (2016) 'The Implementation of Edupreneurship Based on Local Wisdom in Primary School as an Effort to Prepare Indonesian Golden Era', Education in the 21st Century :Responding to Current Issues, pp. 787-793.

Aryanto, S. et al. (2019) 'Ecobrick sebagai Sarana Pengembangan Diri Berbasis Ecopreneurship di Sekolah Dasar', Dwija Cendekia: Jurnal Riset Pedagogik, 3(1), p. 93. doi: 10.20961/jdc.v3i1.34076.

Aryanto, S. and Syaodih, E. (2017) 'Development of Ecopreneurship in Primary School', IJAEDU- International E-Journal of Advances in Education, III(9), pp. 597-602. doi: 10.18768/ijaedu.370428.

Aryanto, S. and Widiansyah, A. (2019) 'Indonesian Journal of Primary Education Kreativitas dalam Pembuatan Sastra Anak Berbasis Ecopreneurship', 3(2), pp. 83-90.

Bellato, A. et al. (2020) 'Is autonomic nervous system function atypical in attention deficit hyperactivity disorder (ADHD)? A systematic review of the evidence', Neuroscience and Biobehavioral Reviews. Elsevier, 108(May 2019), pp. 182-206. doi: 10.1016/j.neubiorev.2019.11.001.

Bikdeli, B. et al. (2020) 'COVID-19 and Thrombotic or Thromboembolic Disease: Implications for Prevention, Antithrombotic Therapy, and Follow-Up: JACC State-of-the-Art Review', Journal of the American College of Cardiology, 75(23), pp. 2950-2973. doi: 10.1016/j.jacc.2020.04.031.

Boehme, R. et al. (2020) 'Sharpened self-other distinction in attention deficit hyperactivity disorder', NeuroImage: Clinical. Elsevier, 27(April), p. 102317. doi: 10.1016/j.nicl.2020.102317.

Clarke, A. R. et al. (2019) 'EEG development in Attention Deficit Hyperactivity Disorder: From child to adult', Clinical Neurophysiology. International Federation of Clinical Neurophysiology, 130(8), pp. 1256-1262. doi: 10.1016/j.clinph.2019.05.001.

Dixon, S. E. A. and Clifford, A. (2007) 'Ecopreneurship - A new approach to managing the triple bottom line', Journal of Organizational Change Management, 20(3), pp. 326-345. doi: 
Sani Aryanto, dkk.

$10.1108 / 09534810710740164$.

Ekayanti, N. W. et al. (2011) 'Upaya Peningkatan Keterampilan Sosial Dalam Pendidikan Biologi Semester Iii Tahun', 1(1), pp. 14-21.

Fan, L. et al. (2020) 'COVID-19 Drug Treatment in China', Current Pharmacology Reports. Current Pharmacology Reports, pp. 1-9. doi: 10.1007/s40495-020-00218-5.

Haataja, E. et al. (2019) 'Teacher's visual attention when scaffolding collaborative mathematical problem solving', Teaching and Teacher Education. Elsevier Ltd, 86, p. 102877. doi: 10.1016/j.tate.2019.102877.

Hayati, D. L. and Apsari, N. C. (2019) 'Pelayanan Khusus Bagi Anak dengan Attentions Deficit Hiperactivity Disorder (ADHD) di Sekolah Inklusif, Prosiding Penelitian \& Pengabdian Mayarakat, 6(1), pp. 108-122.

Indriawati, P. (2013) 'Implementasi Kebijakan Tugas Guru Pembimbing Khusus pada Pendidikan Inklusif di SD Negeri se-Kecamatan Junrejo Batu', Jurnal Kebijakan dan Pengembangan Pendidikan, 1, pp. 49-55.

Kaste, J. A. (2004) 'Scaffolding through cases: Diverse constructivist teaching in the literacy methods course', Teaching and Teacher Education, 20(1), pp. 31-45. doi: 10.1016/j.tate.2003.09.004.

Kiky, A. (2020) 'Manajemen Resiko terhadap Black Swan Event Maret 2020 di Indonesia. Studi Kasus Efek Covid-19 Terhadap Pasar Modal Indonesia', Jurnal Bina Manajemen, 8(2), pp. 90-105.

Lake, E. M. R. et al. (2019) 'The Functional Brain Organization of an Individual Allows Prediction of Measures of Social Abilities Transdiagnostically in Autism and AttentionDeficit/Hyperactivity Disorder', Biological Psychiatry. Elsevier Inc, 86(4), pp. 315-326. doi: 10.1016/j.biopsych.2019.02.019.

Muhonen, H. et al. (2016) 'Scaffolding through dialogic teaching in early school classrooms', Teaching and Teacher Education. Elsevier Ltd, 55, pp. 143-154. doi: 10.1016/j.tate.2016.01.007.

Nacu, C. M. and Avasilcăi, S. (2014) 'Technological Ecopreneurship: Conceptual Approaches', Procedia - Social and Behavioral Sciences, 124, pp. 229-235. doi: 10.1016/j.sbspro.2014.02.481.

Nadiroh and Siregar, S. M. (2019) 'Analisis Kemampuan Memecahkan Permasalahan Lingkungan dan Ekoliterasi Siswa', Jurnal Parameter, 31(2), pp. 96-103.

Van de Pol, J., Volman, M. and Beishuizen, J. (2012) 'Promoting teacher scaffolding in smallgroup work: A contingency perspective', Teaching and Teacher Education. Elsevier Ltd, 28(2), pp. 193-205. doi: 10.1016/j.tate.2011.09.009.

Pratiwi, J. C. (2015) 'Sekolah Inklusi Untuk Anak Berkebutuhan Khusus : Tanggapan Terhadap Tantangan Kedepannya', Prosiding Seminar Nasional Pendidikan Meretas Sukses Publikasi Ilmiah Bidang Pendidikan Jurnal Bereputasi', (November), pp. 237-242. Available at: 
http://jurnal.fkip.uns.ac.id/index.php/pip/article/download/7725/5551.

Sanchis-Gomar, F. et al. (2020) 'Obesity and Outcomes in COVID-19: When an Epidemic and Pandemic Collide', Mayo Clinic Proceedings. Mayo Foundation for Medical Education and Research. doi: 10.1016/j.mayocp.2020.05.006.

Schaltegger, S. (2014) 'A Framework for Ecopreneurship', Greener Management International, 2002(38), pp. 45-58. doi: 10.9774/gleaf.3062.2002.su.00006.

Schaper, M. (2002) 'The essence of ecopreneurship', Greener Management International, (38), pp. 26-30. doi: 10.9774/GLEAF.3062.2002.su.00004.

Schutz, K. M., Danielson, K. A. and Cohen, J. (2019) 'Approximations in English language arts: Scaffolding a shared teaching practice', Teaching and Teacher Education. Elsevier Ltd, 81, pp. 100-111. doi: 10.1016/j.tate.2019.01.004.

Singh, R. and Subedi, M. (2020) 'COVID-19 and Stigma: Social discrimination towards frontline healthcare providers and COVID-19 recovered patients in Nepal', Asian Journal of Psychiatry. Elsevier, 53(June), p. 102222. doi: 10.1016/j.ajp.2020.102222.

Sulistyadi, H. K. (2014) 'Implementasi Kebijakan Penyelenggaraan Layanan Pendidikan Inklusif di Kabupaten Sidoarjo', Kebijakan dan Manajemen Publik, 2(1), pp. 1-10.

Uslu, Y. D., Hancıoğlu, Y. and Demir, E. (2015) 'Applicability to Green Entrepreneurship in Turkey: A Situation Analysis', Procedia - Social and Behavioral Sciences, 195, pp. 1238-1245. doi: 10.1016/j.sbspro.2015.06.266.

Wati, E. (2014) 'Manajemen Pendidikan Inklusi Di Sekolah Dasar Negeri 32 Kota Banda Aceh', Jurnal Ilmiah Didaktika, 14(2), pp. 368-378. doi: 10.22373/jid.v14i2.508. 